\title{
1 The frequency of syncope in the Latin of the empire: a statistical and dialectological study based on the analysis of inscriptions
}

\author{
Bonae Memoriae \\ József Herman \\ (1924-2005)
}

\section{Introduction}

About the frequency of syncope ${ }^{1}$ in the Latin of the Empire one can observe two opposite views circulating in the literature: on the one hand scholars who are working principally with the Latin inscriptional material commonly say that syncope "is not particularly widespread" (Gaeng 1968: 288) or "was not a common phenomenon in Vulgar Latin inscriptions" (Omeltchenko 1977: 457). Moreover, Cross, who first treated inscriptions as for the incidence of syncope systematically, says: "In general, throughout the whole of the Roman world ... there is a surprising lack of syncope” (Cross 1930: 99).

On the other hand, scholars, mainly of Romance rather than of Latin, who rely on sources of Latin other than inscriptions or on evidences of the Romance languages, are prone to formulate the opposite view. First of all the statement of Väänänen has exerted a significant influence on the related literature, who stated that syncope is a phenomenon of an eminently popular or familiar type and that out of 227 'mistakes' censured by the Appendix Probi, 25 instances

1 A compact presentation of the problem of syncope in the history of Latin has been recently yielded by Adams (2013: 90-100).

Note: The present paper has been prepared within the framework of the project OTKA (Hungarian Scientific Research Fund) No. K 81864 and K 108399 entitled "Computerized Historical Linguistic Database of Latin Inscriptions of the Imperial Age” (see: http://lldb.elte.hu/). I wish to express my gratitude to Katalin Horváth and Ádám Rung for their help in the revision of the English text. 
refer to syncope. ${ }^{2}$ The impact of Väänänen's statement can be clearly seen in Loporcaro's study (Loporcaro 2011: 58 f.), when he formulates as follows: "Syncope of the post-tonic vowel of proparoxytones, especially, clearly has a common (pan-Romance) core, rooted in (late) Latin, where it is massively attested [emphasis mine]: the Appendix Probi offers several examples of proscribed popular forms like calda for CALIDA 'hot', oclus for OCULUS 'eye', veclus for VETULUS 'old', virdis for VIRIDIS 'green', which must have been in common use in the spoken language of the time (probably mid fifth century ...) and underlie all Romance outcomes". ${ }^{3}$ Then Loporcaro nevertheless states that "on the other hand, syncope clearly developed at a different pace and to different extents in the individual (Romance) languages" ${ }^{4}$ and that "a general tendency can be recognized, with western Romance displaying more extensive syncope than eastern, and Italy and Sardinian in between".

In short, scholars who regard syncope as a frequent phenomenon in late Latin, usually base their reasoning on generalizing the observations from the list of the late Roman Appendix Probi with its relatively high proportion of syncope $(226: 25=11 \%) .^{5}$

This state of research generalizing in both directions (i.e. syncope was scarce everywhere vs. it was frequent overall) was (or at least could have been) challenged by a brief and excellent (but in the literature, in essence, unnoticed) study of J. Herman (1990 = 1984: 56-59), who found that in this regard the Latin speaking part of the Empire was not homogeneous at all. Founded merely on limited corpora or on data taken from the related secondary literature but with his subtle methodology Herman was able to reveal significant differences in the distribution of syncope both geographically (e.g. between the Eastern and Western regions of Northern Italy) and chronologically (e.g. between the early and later periods in the various parts of Gaul). Herman, however, regarded his results as provisional and the entire question as worth

2 Väänänen ${ }^{3} 1981$, 41: "La syncope est un phénomène d'aspect éminemment populaire ou familier. Sur 227 «fautes » relevées dans l’Appendix Probi, 25 se rapportent à la syncope.” (also cited by Adams 2013: 91).

3 Loporcaro's examples are: “CALIDAM 'hot' > CALDAM > Fr. chaude, It. calda, Log. (Srd.) kalda, Rom. caldă; FRIGIDAM 'cold' > FRICDAM > Fr. froide, It. fredda, Log. (Srd.) fritta; VIRIDEM 'green' > VIRDEM > Fr. vert, It. verde, Log. (Srd.) bilde, Ro. verde; OCULUM 'eye' > OCLUM $>$ Fr. oeil, It. occhio, Log. (Srd.), 'o:3u, Ro. ochi.”

4 One of his examples for this difference is "HEDERAM 'ivy': Sp. hiedra, Pt. hera, Cat. eura, Prv. elra, (Ofr. iere $>$ ) Fr. lierre vs. it. edera, Ro. iederă."

5 Or on attempting to trace back (mainly western) Romance phenomena to their (alleged) late Latin dialectological background cf. the ineffectual attempts of Gaeng (1968: 271 f.) and Omeltchenko (1977: 458f.). 
re-examining in detail ("la question mériterait d' être réexaminée en détail", Herman 1990 = 1984: 57). Therefore in my paper I intend to re-examine the problem of the frequency of syncope and to continue and expand the investigations started by Herman with the help of an upgraded version of his methodology and based on the data collected to date in the "Computerized Historical Linguistic Database of Latin Inscriptions of the Imperial Age”. 6

\section{Methodology}

For our investigation we have selected about the same territorial units as Herman did: in this survey I will consider Aquitania, Belgica and Narbonensis of the four provinces of Roman Gaul, Venetia-Histria of the north Italian provinces, and Dalmatia of the provinces of Illyricum. I will treat these provinces in two chronological sections: 1 . early Empire, i.e., the $1-3^{\text {rd }}$ centuries A. D.; 2. later Empire i.e. the era starting with the $4^{\text {th }}$ century and lasting up to the $6^{\text {th }}$ or $7^{\text {th }}$, and sometimes even $8^{\text {th }}$ or $9^{\text {th }}$ century A. D., depending on the history and the epigraphic culture of each province. As for the methodology used in this survey it should be mentioned here that I will examine the relative frequency of syncope, i.e. the frequency of mistakes referring to vowel deletion in relation to mistakes relating to other phonological phenomena. ${ }^{7}$ First, I will set the figure for syncope against the number of all vocalic and all consonantal errors, displayed in every first and third chart of each province under consideration labelled as undifferentiated charts. Then, again for every one province I'll chart the frequency of syncope, this time divided in pretonic and posttonic

6 Henceforth we refer to it as the Database (see: http://lldb.elte.hu/); for a general description of the Database and its Methodology see Adamik (2009: 2012).

7 In this investigation by exluding those data forms with a parallel nominal or verbal morphosyntactic alternative code (chosen from the lists labelled as 'Nominalia' or 'Verbalia' in the Database) we consider only those data forms in our Database with phonetic main codes (chosen from the lists labelled as 'Vocalismus' or 'Consonantismus' in the Database) such as tumolo for tumulo (LLDB-2977), septemo for septimo (LLDB-13780) and visit for vixit (e.g. LLDB-7660) etc. This procedure is inevitable because such forms as annus for annos (e.g. LLDB-11843), mensis for menses (e.g. LLDB-7012), co(ho)rti for cohortis (e.g. LLDB-14045), voluntate for voluntatem (e.g. LLDB-4158) and iacit for iacet (LLDB-14646), quiescet for quiescit (LLDB-8079) etc. can be interpreted not only as incidences of phonological changes but also as incidences of confusions between either cases or declensions or conjugations - inseparably from each other. Accordingly, we have excluded also those data forms with a parallel alternative code chosen from the list labelled as 'Syntcatica etc.' in the Database, e.g. archaisms such as vivos for vivus (e.g. LLDB-231) or possible recompositions such as perdedit for perdidit (LLDB-4335) etc. 
syncope, merely in relation to the figures for the $o / u$ and $e / i$ mergers, the two most important processes of the reorganization of the vowel system in Vulgar Latin, in order to get a more realistic picture of the frequency and productivity of the phenomenon under consideration. ${ }^{8}$ These, i.e. every second and fourth chart of each selected province are here labelled as differentiated or refined charts. Finally I'll set tables for each province containing the particular occurrences for pretonic and posttonic syncope, subdividing their instances in common and proper nouns (abbreviated in the tables below as CN and PN). In their sections labelled as 'Contrasts' these tables also contain words (e.g. titulus and tumulus) that have both their syncopated (e.g. titlum and tumlum) and unsyncopated but otherwise misspelled variants (e.g. tetolo and tomolo) or only the latter, i.e. the unsyncopated variants. With the help of this contrastive method, suggested by Herman $(1990=1984$ : 58$)$, we can test the absence or presence of syncope in a given area at a given span of time. Thus, if there are there and then several items for unsyncopated but otherwise misspelled variant such as tetolo or tomolo but no, or only isolated examples are to be found of syncopated ones such as titlum or tumlum, then the absence of syncope must be taken at face value.

\section{Quantitative and qualitative statistical analysis}

\subsection{Aquitania}

After this methodological introduction let us examine Aquitania as the first province to be analysed in this context. ${ }^{9}$ The distribution of the data from this province can be charted as follows, see the next Figures 1.1-1.4.

From the distributional patterns of the undifferentiated Figures 1.1 (226 items $=100 \%)$ and $1.3(210$ items $=100 \%)$ we can conclude that Aquitania

\footnotetext{
8 Pretonic and posttonic syncope are labelled as 'syncope praetonica' and 'syncope posttonica' in the Database (they are present in the code list of 'Vocalismus'). In addition we added also the scarce items of epenthesis or anaptyxe in the footnotes below containing the data for syncopes, but we did not charted them together with the syncopes, because the epenthesis or anaptyxe, albeit it is sometimes treated together with syncope as a kind of its hypercorrection, really has nothing to do with it, see Leumann (1977: 104).

9 The data pertaining to this province has been recorded by Krisztina Fodor from the corpora of ILA, CIL, RICG, AE and ILTG (for resolving abbreviations of inscriptional corpora used in this survey see EDCS, http://www.manfredclauss.de/abkuerz.html).
} 

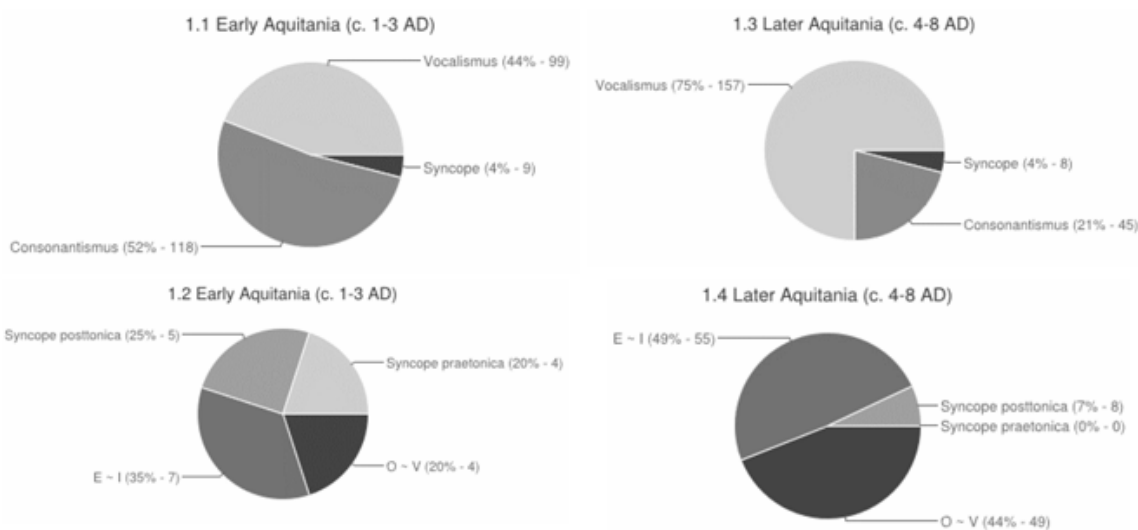

Fig. $1^{10}$

does not show any difference between its early and later data profile. The proportion of syncope was very low in both time spans under consideration: $4 \%$ (= 9 items) in early and again $4 \%$ (= 8 items) in later times. This virtual constancy, however, becomes insignificant and illusory, if we consider the refined or differentiated figures $1.2(20$ items $=100 \%)$ and $1.4(112$ items $=100 \%)$, where we can actually notice a significant difference between the early and later period of the province. While the common proportion of the two types of syncope was as high as $45 \%$ in the early period (SyPr 20\% + SyPo 25\%), it dropped significantly to $7 \%$ in later times (SyPr 0\% + SyPo 7\%) ${ }^{11}$ Parallel to this decrease of syncopes, the proportion of the $e / i$ and $o / u$ mergers extended perceptibly from early $55 \%(35 \%+20 \%)$ up to later $93 \%(49 \%+44 \%) .{ }^{12}$

The evidence of these two opposite processes, i.e. the decrease of syncope and increase of the $e / i$ and $o / u$ mergers is corroborated by the contrastive data displayed in Table 1 under the subheading Contrasts.

10 All the figures displayed in the study are prepared with the charting module of the Database and represent the status on 31.12. 2013.

11 The items for early syncopes are recorded in the Database under the following LLDB-numbers: 158, 163, 1320, 1340, 1349, 1365, 2777, 2826, 21666 (=9), those for later ones under LLDB2931, 2938, 2941, 2950, 3193, 3198, 3226, 3959 (= 8); those undated items left here out of consideration are recorded under LLDB-2651, 3033, $3373(=3)$. The single one item of epenthesis (LLDB-21535) originates from the early period.

12 As for the $e / i$ and $o / u$ mergers there have been recorded the following figures (Code-name: figure) from the early period: î > E: 1, é > I : 1, é: > I: 3, e > I: $2(=7)$ and ú > 0: 2, o > V: 1, $\mathrm{u}>$ O: $1(=4)$; from the later period: 1 > E: 5 , é: $>$ I: 15 , e: $>$ I: $3, \mathrm{i}>\mathrm{E}: 30$, e $>$ I: $2(=55)$ and ó: > V: 1, ú > O: 20, u > 0: 20, o > V: 8 (= 49). 
Tab. 1

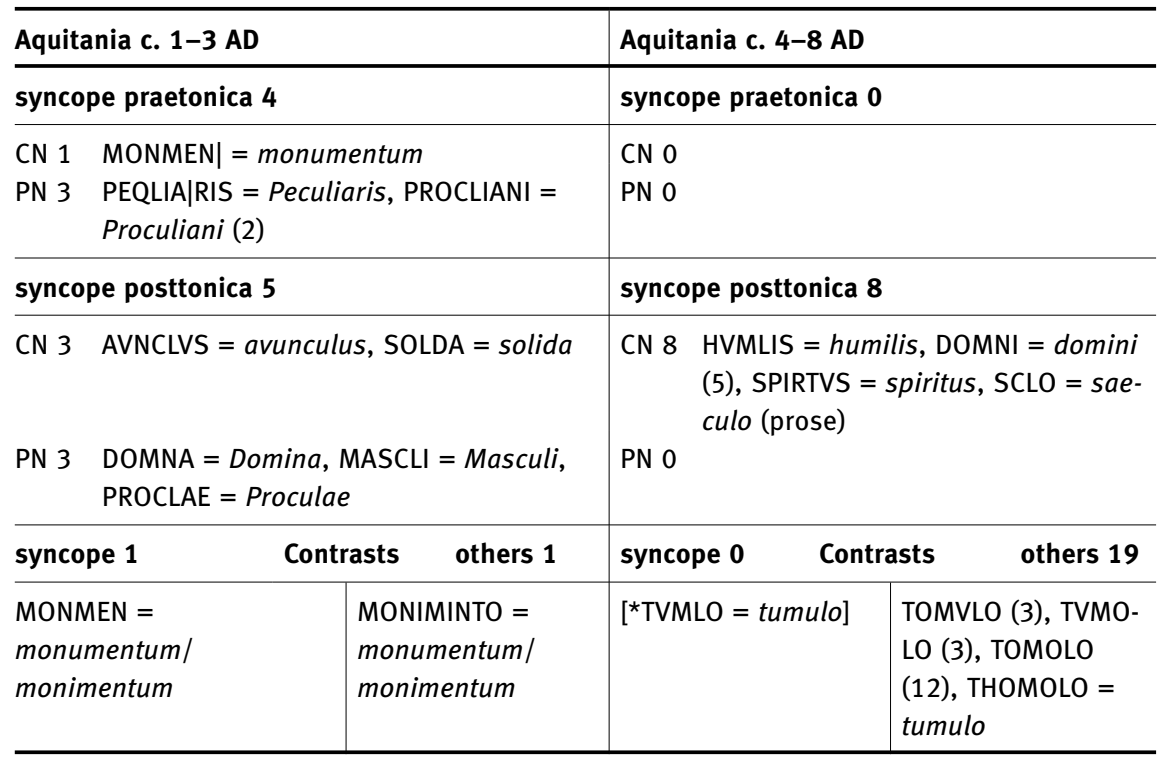

While in early Aquitania we were able to register one syncopated (MONMEN) and one unsyncopated but otherwise misspelled variant (MONIMINTO) of the same noun (monumentum/monimentum) side by side, in the later province we have not been able to match any example of a syncopated form (such as *TVMLO) to the several (19) occurrences of the unsyncopated but otherwise misspelled variants (such as TOMOLO) of the same noun (tumulus). In short, by later times syncope has become evanescent in the Latin of Aquitania.

\subsection{Belgica}

The second province to be presented here is Belgica. ${ }^{13}$ The distribution of the data from this province can be charted as follows, see the next Figures 2.1-2.4. From the distributional patterns of the undifferentiated Figures $2.1(192$ items $=100 \%)$ and $2.3(291$ items $=100 \%)$ it seems that, contrary to Aquitania, Belgica already displays a significant difference between its early and later data profile. The $5 \%$ (already quite low) proportion of syncope in the early

13 The data pertaining to this province has been recorded mainly by Krisztina Fodor (and also by Lehel Ambrus) from the corpora of RICG, ILingons, ILB2, CSIR-D, FITrier, Finke, Ness-Lieb, Nesselhauf, Schillinger, ILTG and Lehner. 

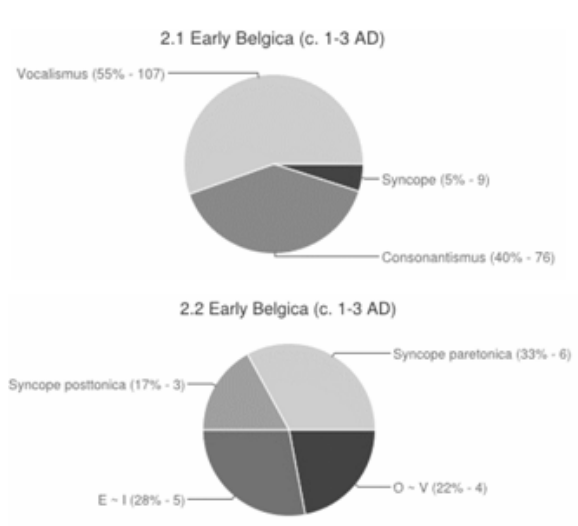
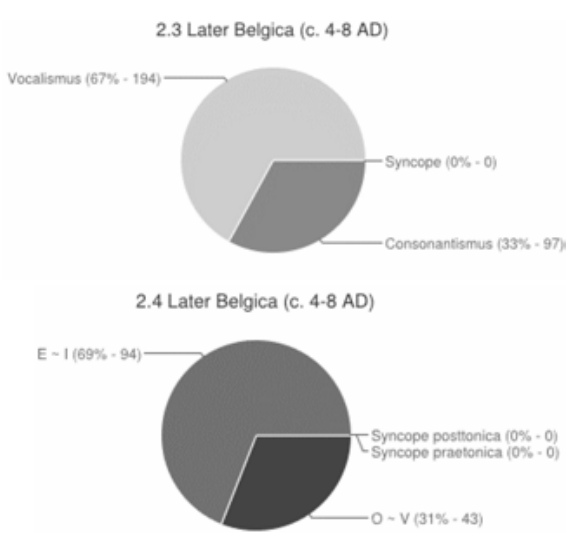

Fig. 2

province dropped to $0 \%$ in the later province. If we consider the refined or differentiated figures $2.2(18$ items $=100 \%)$ and $2.4(137$ items $=100 \%$, we can observe a much more significant difference between the early and the later period of the province. While the common proportion of the two types of syncope was as high as $50 \%$ in the early period (SyPr 33\% + SyPo 17\%), it dropped drastically to $0 \%$ in later times (SyPr 0\% + SyPo 0\%). ${ }^{14}$ Parallel to this disappearing of syncopes, the proportion of the $e / i$ and $o / u$ mergers extended extremely from early $50 \%(28 \%+22 \%)$ up to later $100 \%(69 \%+31 \%) .{ }^{15}$ The total absence of syncope from the later province, observed by Herman $(1990=$ 1984, 58), can be spectacularly and completely corroborated by the contrastive data displayed in Table $2 .{ }^{16}$

14 The items for early syncopes are recorded in the Database under the following LLDB-numbers: LLDB-4474, 4555, 4893, 4902, 5076, 5077, 5085, 5101, 5125 (= 9); the one undated item left here out of consideration is recorded under LLDB-5212. The items for epenthesis not indicated on the figures 2.2 and 2.4 are the following: from the early period LLDB-5062, from the later one LLDB-7927 and 8426.

15 As for the $e / i$ and $o / u$ mergers there have been recorded the following figures (Code-name: figure) from the early period: é $>$ I : 3, e > I: 1, i > E: 1(= 5) and o > V: 1, o: > V: 1, u > 0: 2 (= 4) resp.; from the later period: é > I : 2, é: > I: 10, í: > E: 4, í > E: 42, i > E: 28, e > I: 2, e: > I: 6 (= 94) and ó > V: 1, ó: > V: 3, ú > 0: 4, o: > V: 1, o > V: 3, u > O: 31 (= 43) resp.

16 What is more, also the early preponderance of syncope ( $5 \%$, resp. $48 \%)$ might be explained away by the data displayed in Table 2. On the one hand we can notice that all the 9 occurrences of syncope are to be found in proper names that have their own spreading features. On the other hand, also the contrastive material displayed in Table 2 under subheading Contrasts corroborates the doubtfulness of early occurrences of syncope: to the 6 incidences of the unsyncopated but otherwise misspelled variants of the noun monumentum/monimentum, e.g. MONIMINTO, we can not match any example of a syncopated form (such as ${ }^{\star}$ MONMENTVM). 
Tab. 2

\begin{tabular}{|c|c|c|c|}
\hline \multicolumn{2}{|l|}{ Belgica C. 1-3 AD } & \multicolumn{2}{|l|}{ Belgica C. 4-8 AD } \\
\hline \multicolumn{2}{|c|}{ syncope praetonica 6} & \multicolumn{2}{|l|}{ syncope praetonica 0} \\
\hline \multicolumn{2}{|c|}{$\begin{array}{l}\text { DECM|ANI = Decimani, DECMNVS = } \\
\text { Decimanus/Deciminus, DECMILLA = } \\
\text { Decimilla, DECMI|LLVS = Decimillus, } \\
\text { MAXMINVS = Maximinus (2) }\end{array}$} & \multicolumn{2}{|l|}{$\begin{array}{ll}\text { CN } & 0 \\
\text { PN } & 0\end{array}$} \\
\hline \multicolumn{2}{|c|}{ syncope posttonica 3} & \multicolumn{2}{|l|}{ syncope posttonica 0} \\
\hline \multicolumn{2}{|c|}{$\begin{array}{ll}\text { CN } 0 & \\
\text { PN } 3 & \text { ACVM } \mid \text { NA = Acumina, HILARICLVS = } \\
& \text { Hilariculus, PATERCLV } \mid=\text { Paterculus }\end{array}$} & \multicolumn{2}{|l|}{$\begin{array}{l}\text { CN } 0 \\
\text { PN } 0\end{array}$} \\
\hline \multicolumn{2}{|l|}{ syncope 0} & \multicolumn{2}{|c|}{ syncope $0 \quad$ Contrasts $\quad$ others 39} \\
\hline $\begin{array}{l}{[* \text { MONMENTVM }=} \\
\text { monumentum } / \\
\text { monimentum }]\end{array}$ & $\begin{array}{l}\text { MONI|MET[VM], } \\
\text { MONI|MINTO, } \\
\text { MO|NIMI|[NTVM], } \\
\text { MONIM|ENTON|, } \\
\text { MVNIMIN|[TVM], } \\
\text { MONIM|ENTV| = } \\
\text { monumentum/ } \\
\text { monimentum }\end{array}$ & $\begin{array}{l}{\left[{ }^{\star} \mathrm{SAECLO}=\text { saeculo }\right]} \\
{\left[{ }^{\star} \mathrm{POSTVS}=\text { positus }\right]} \\
{\left[{ }^{\star} \mathrm{TVMLO}=\text { tumulo }\right]} \\
{\left[{ }^{*} \mathrm{TITLVM}=\text { titulum }\right]}\end{array}$ & $\begin{array}{l}\text { SECVLO = saeculo (2) } \\
\text { POSETVS = positus } \\
\text { TOMOLO = tumulo } \\
\text { TE|TVLV, TETVLVM (9), } \\
\text { TETOLVM (12), } \\
\text { TETOLVN (2), } \\
\text { [T]ETVLO, TITOLVM (5), } \\
\text { TITOLV, TITOLO, } \\
\text { TITVLV (3), TITVLO = } \\
\text { titulum }\end{array}$ \\
\hline
\end{tabular}

All the 39 items of unsyncopated but otherwise misspelled forms, among them 35 occurrences of the several variants of the word titulus, such as TETOLVM, TITOLO etc. lack their syncopated counterparts such as ${ }^{\star}$ TITLVM attested in other provinces. ${ }^{17}$

\subsection{Narbonensis}

The third province to be examined in this survey is Gallia Narbonensis. ${ }^{18}$ The distribution of the data from this province can be charted as follows, see the next Figures 3.1-3.4.

17 In Pannonia 5, in Moesia Inferior 3, in Dacia 2 times, and in Hispania Citerior once among the data forms to date recorded in the LLDB-Database.

18 The data pertaining to this province has been recorded by Zsuzsanna Ötvös from the corpora of RICG, ILN, ICalvet, INimes, ILHSavoie and RISch. 


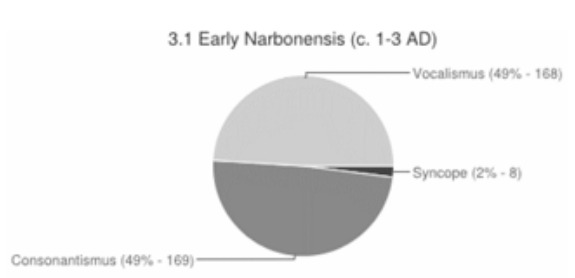

3.2 Early Narbonensis (c. 1-3 AD)

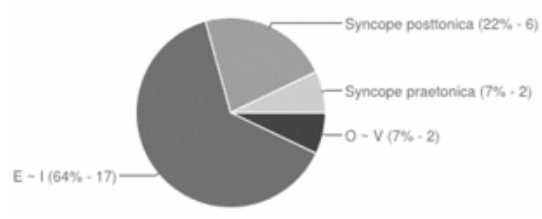

3.3 Later Narbonensis (c. 4-8 AD)

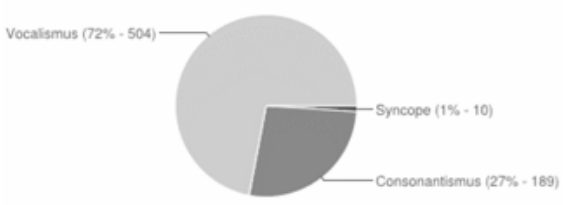

3.4 Later Narbonensis (c. 4-8 AD)

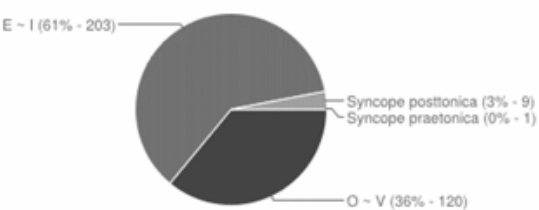

Fig. 3

From the distributional schemes of the undifferentiated Figures 3.1 ( 345 items $=$ $100 \%)$ and $3.3(703$ items $=100 \%)$ we can conclude that Narbonensis shows little difference between its early and later data profile. The $2 \%$ low proportion of syncope in the early province dropped to $1 \%$ in the later province. But if we also consider the refined or differentiated figures $3.2(27$ items $=100 \%)$ and 3.4 (333 items $=100 \%$ ), we can notice a much more significant decrease between the early and the later period of the province. While the common proportion of the two types of syncope was as high as $29 \%$ in the early period (SyPr $7 \%+$ SyPo $22 \%$ ), it dropped significantly - to 3\% - in later times (SyPr 0\%+ SyPo $3 \%) .{ }^{19}$ Parallel to this decrease of syncopes, the proportion of the $e / i$ and $o / u$ mergers extended perceptibly from early $71 \%(64 \%+7 \%)$ up to later $97 \%$ $(61 \%+36 \%) .20$

The evidence of these two opposite processes, i.e. the decrease of syncope and the increase of the $e / i$ and $o / u$ mergers is partly corroborated but also

19 The items for early syncopes are recorded in the Database under the following LLDB-numbers: 55, 1537, 2242, 2257, 15646, 15651, 15790, $17382(=8)$, those for later ones under LLDB-4134, 4203, 4244, 4269, 7466, 9566, 10276, 13995, 14000, 14007 (=10); The single one undated item left here out of consideration is recorded under LLDB-2561. For epenthesis we could not record any item.

20 As for the $e / i$ and $o / u$ mergers there have been recorded the following figures (Code-name: figure) from the early period: î > E: 5, í: > E: 1, é: > I: 2, é > I : 1, e: > I: 1, e > I: 2, i > E: 5 (= 17) and ó > V: 1, u > O: $1(=2)$ resp.; from the later period: í > E: 37, í: > E: 4, é > I : 5, é: > I: 33, e > I: 12, i > E: 100, e: > I: 7, i: > E: 5 (=203) and ó > V: 4, ú > 0: 29, ó: > V: 12, o > V: 5, o: > V: 4, u > 0: $66(=120)$ resp. 
Tab. 3

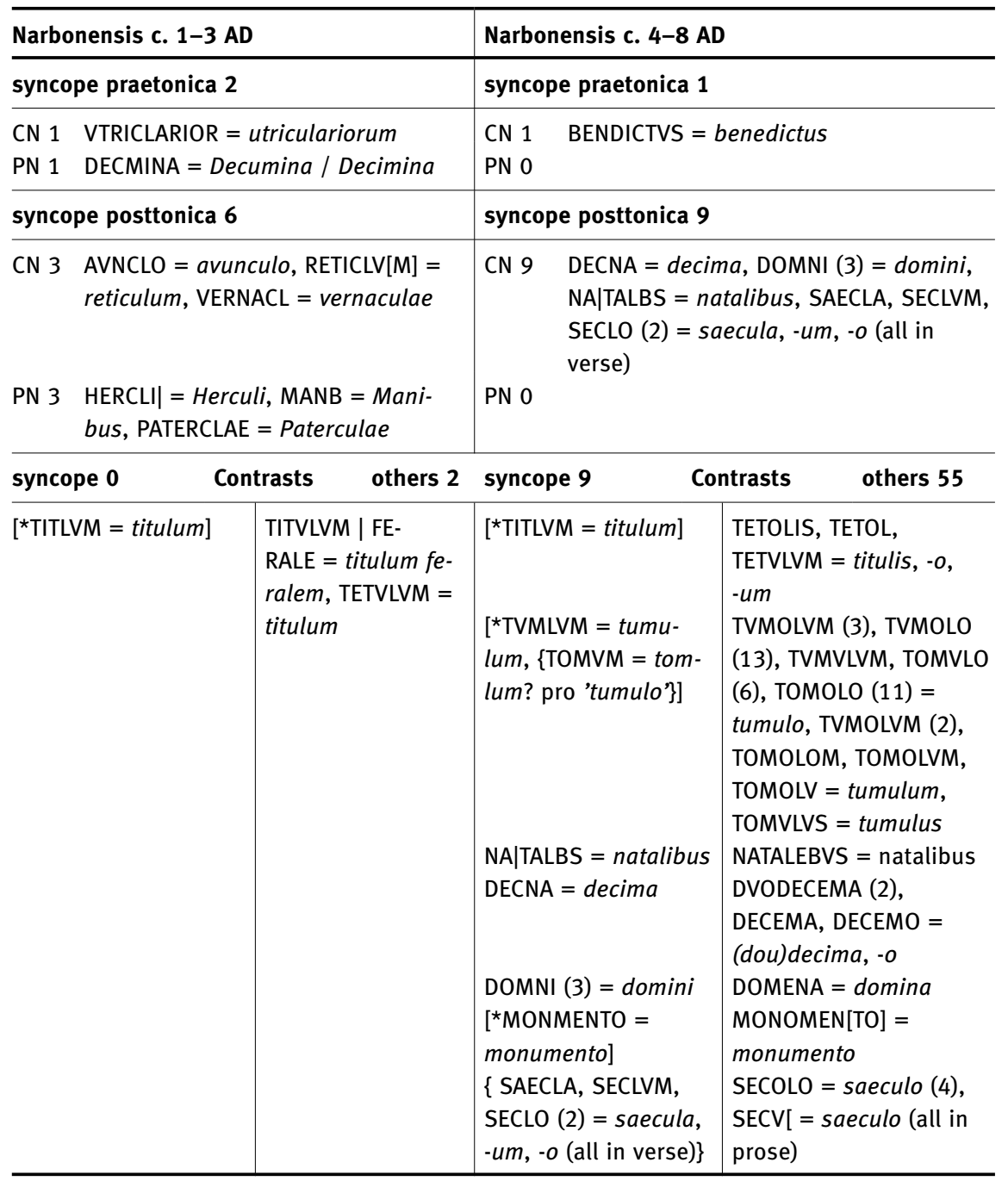

slightly modified by the contrastive data displayed in Table 3 under the subheading Contrasts.

While in early Narbonensis we were not able to register any syncopated word (such as *TITLVM) and only two unsyncopated but otherwise misspelled forms (a neuter TITVLVM and a form TETVLVM), in the later province we were able to match the syncopated forms DOMNI for domini, DECNA for decima and 
NATALBVS for natalibus to their unsyncopated but otherwise misspelled counterparts DOMENA for domina, DECEMA for decima (occurring 4 times) and NATALEBVS for natalibus. According to the testimony of these syncopated and unsyncopated counterparts and to the finding that the later instances of syncope are recorded not in proper nouns but only in common nouns, we might conclude that, despite the later decline of syncope established statistically above in the refined figures, this phonological process was more vivid in later than in early Narbonensis. But one should also take into consideration two striking facts against this incautious conclusion: firstly, some syncopated and unsyncopated counterparts in the later material of the province such as SECLO besides SECOLO are to be left out of consideration, because all the unsyncopated forms of this word are recorded in prose and conversely all the syncopated variants occur in verse, where they are correctly used according the norms of classical versification. ${ }^{21}$ Secondly, the predominant part of the unsyncopated but otherwise misspelled forms, i.e. 44 items of 55, such as TOMOLO, TVMOLVM etc. (in all 40 occurrences), TETOLIS, TETVLVM etc. (in all 3 items) and a MONOMEN[TO] lack all syncopated counterparts such as *TVMLVM and ${ }^{\star}$ TITLVM or ${ }^{\star}$ MONMENTO. In short, syncope was an apparently present but isolated phenomenon both in early and later Narbonensis.

\subsection{Venetia-Histria}

The fourth province to be examined in my paper is Venetia-Histria. ${ }^{22}$ The distribution of the data selected for this survey can be charted as follows, see the next Figures 4.1-4.4.

Judged by the distributional patterns of the undifferentiated Figures 4.1 $(424$ items $=100 \%)$ and $4.3(705$ items $=100 \%)$, Venetia-Histria shows little difference between its early and later data profile. The $3 \%$ proportion of syncope in the early province dropped to $2 \%$ in the later province. But considering the refined or differentiated figures 4.2 (33 items $=100 \%)$ and 4.4 (133 items = $100 \%$ ), we can notice a much more significant decrease between the early and the later period of the province. While the common proportion of the two types of syncope was as high as 36\% in the early period (SyPr 24\% + SyPo 12\%), it

21 E.g. saecli in Ovid, Epistulae ex Ponto 2, 8, 25.

22 The data pertaining to this province has been recorded by Ákos Zimonyi from the corpora of InscrAqu, InscrIt, Pais, CIL, AE and IEAquil. 

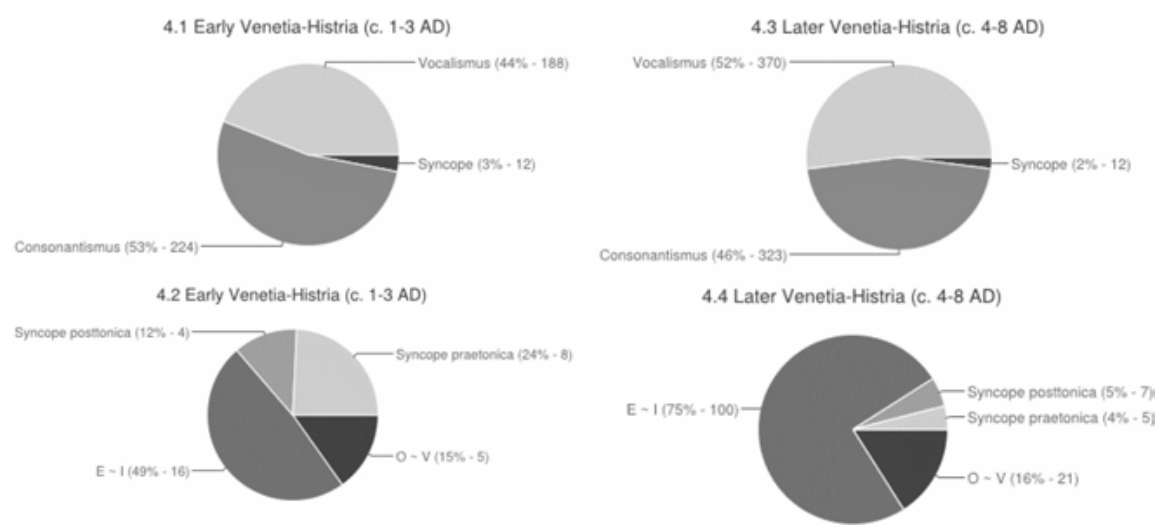

Fig. 4

Tab. 4

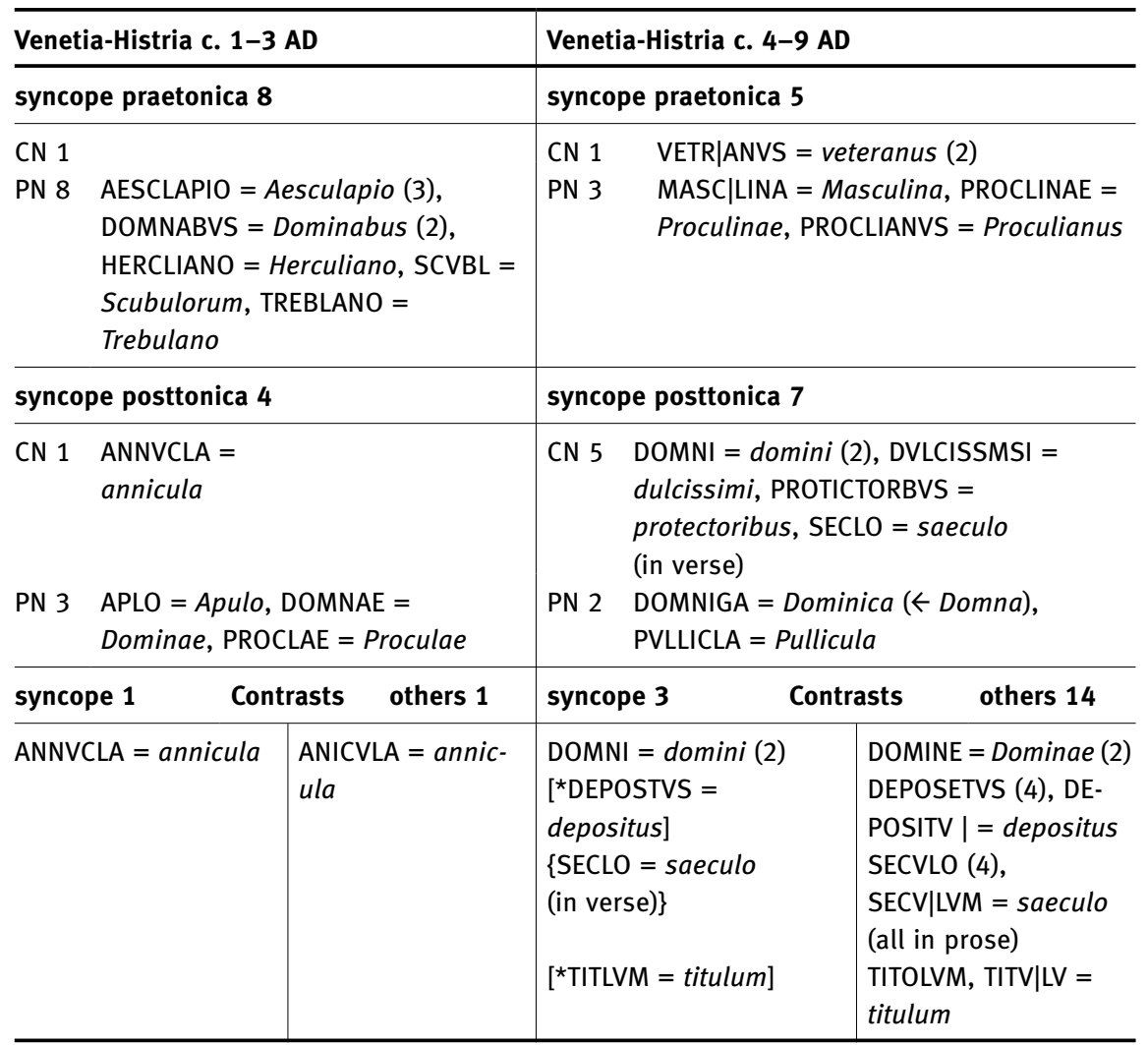


dropped significantly to $9 \%$ in later times (SyPr 4\% + SyPo 5\%). ${ }^{23}$ Parallel to this decrease of syncopes the proportion of the $e / i$ and $o / u$ mergers extended perceptibly from early $64 \%(49 \%+15 \%)$ up to later $91 \%(75 \%+16 \%) .{ }^{24}$

The evidence of these two opposite processes, i.e. the decrease of syncope and the increase of the $e / i$ and $o / u$ mergers is corroborated by the contrastive data displayed in Table 4 under the subheading Contrasts.

In early Venetia-Histria we were able to register one syncopated (ANNVCLA) and one unsyncopated but otherwise misspelled variant (ANICVLA) of the same noun (annicula) side by side. At the same time we were able to match merely two proper examples of a syncopated form (DOMNI) to just two occurrences of the unsyncopated but otherwise misspelled variants (DOMINE) of the noun pair dominus/domina in the later province. The further contrastive data displayed in Table 4 confirm the isolated nature of syncope phenomena in the later province even more. On the one hand the syncopated and unsyncopated counterparts of saeculum, i.e. SECLO resp. SECVLO are to be left out of consideration from the contrastive examples of later Venetia-Histria according to the considerations above. On the other hand, a significant part of the unsyncopated but otherwise misspelled forms, i.e. 7 items of 14, such as DEPOSETVS or TITOLVM etc. lack their syncopated counterparts such as *DEPOSTVS or *TITLVM again attested in other provinces. In short, syncope was a present but isolated phenomenon in later Venetia-Histria. ${ }^{25}$

23 The items for early syncopes are recorded in the Database under the following LLDB-numbers: 11239, 11240, 11241, 11251, 11529, 12609, 12612, 12637, 13001, 13002, 17158, 20944 (= 12), those for later ones under LLDB-11865, 11979, 12115, 12219, 12303, 12550, 13000, 16042, 21190, 21279, 22953, 23432 (=12); The undated items left here out of consideration are recorded under LLDB-16023, 21280, 23363, 23553, 23560, 23571, 23715, 24024 (= 8). The items for epenthesis are the following: from the early period LLDB-12987 and 15995, from the later one LLDB-12415 resp. (there is also an undated item: LLDB-23604).

24 As for the $e / i$ and $o / u$ mergers there have been recorded the following figures (Code-name: figure) from the early period: é > I : 3, í: > E: 1, e > I: 2, i: > E: 2, i > E: $8(=16)$ and o > V: 1 , $\mathrm{u}>$ O: 3, o: > V: 1 (=5) resp.; from the later period: é: > I: 6, é > I : 1, í: > E: 6, í > E: 11, i: > E: 4, i > E: 59, e: > I: 7, e > I: $6(=100)$ and ó > V: 3, ú: > O: 1, ó: > V: 4, o: > V: 1, o > V: 2, u: > O: 1, $\mathrm{u}>$ 0: 7 (=21) resp.

25 At this point, despite the fact that in our Database the entire province is not yet processed, we might modify the statement of Herman (1990 = 1984: 57): "La syncope est courant dans le Nord-Est: Vénétie, Istrie, Aquilée et ses environs”, and (p. 58): "La syncope est présente en masse dans le latin épigraphique du Nord-Est de l'Italie, alors que les dialectes romans qui s'y parlent aujourd'hui y sont plutôt réfractaires." Herman based his statement on the seemingly numerous data displayed by Zamboni (1965-66: 509f.) that are, however, set out rather undifferentiated and contain also several undated occurrences and those of the republican era: both categories are inappropiate for a chronologically based statistical survey as here. This means 


\subsection{Dalmatia}

The fifth and last province to be presented here is Dalmatia. ${ }^{26}$ The distribution of the data selected for my investigation can be charted as follows, see the next Figures 5.1-5.4.

From the distributional patterns of the undifferentiated Figures 5.1 (495 items $=100 \%)$ and $5.3(653$ items $=100 \%)$, we can see that Dalmatia shows a small difference between its early and later data profile. The $5 \%$ proportion of syncope in the early province dropped to $2 \%$ in the later province. But if we consider the refined or differentiated figures $5.2(52$ items $=100 \%)$ and 5.4 (157 items $=100 \%$ ), we can notice a much more significant decrease between the early and the later period of the province. While the common proportion of the two types of syncope was as high as $45 \%$ in the early period (SyPr 10\% + SyPo $35 \%$ ), it dropped significantly to $11 \%$ in later times (SyPr 3\% + SyPo 8\%). ${ }^{27}$ Of course, the proportion of the $e / i$ and $o / u$ mergers extended perceptibly from
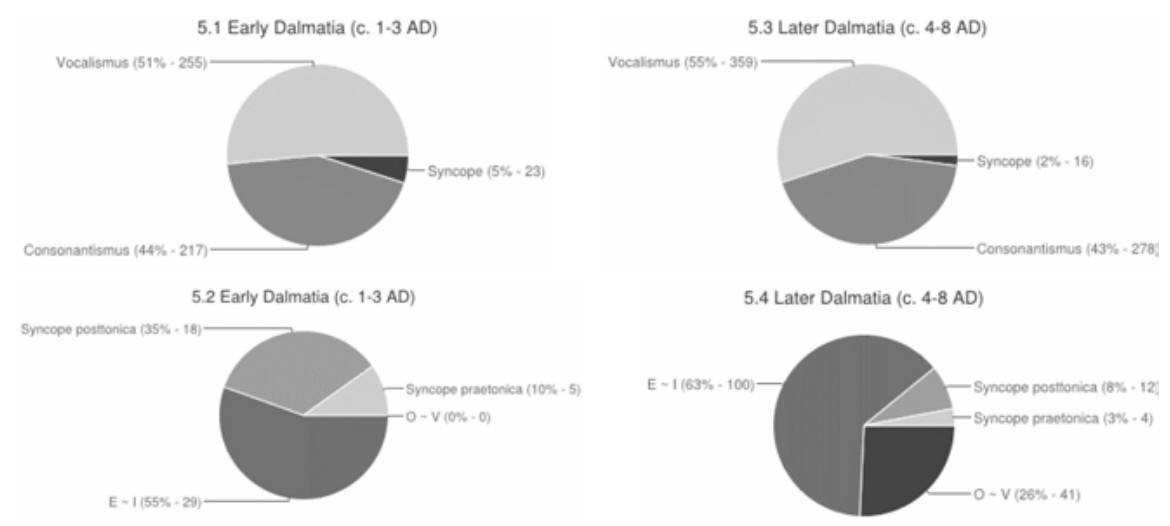

Fig. 5

that in this respect there is not any discrepancy between Latin of old and Romance of modern times as for this area.

26 The data pertaining to this province has been recorded by myself from the corpora of ILJug and Salona (abbreviated in EDCS as Salona-04).

27 The items for early syncopes are recorded in the Database under the following LLDB-numbers: $868,964,1386,3427,3432,3896,4045,4054,4110,4701,5276,5281,5863,9173,9253$, $9289,14353,14354,14403,14405,14415,14603,22189$ (= 23), those for later ones under LLDB1820, 1825, 3442, 9306, 10843, 10849, 14171, 14246, 14266, 14273, 14359, 14361, 14375, 18400, 20278, 20279 (= 16); the single one undated item left here out of consideration is recorded under LLDB-14289. The single one item for epenthesis originates from the later period and is the following: LLDB-223. 
Tab. 5

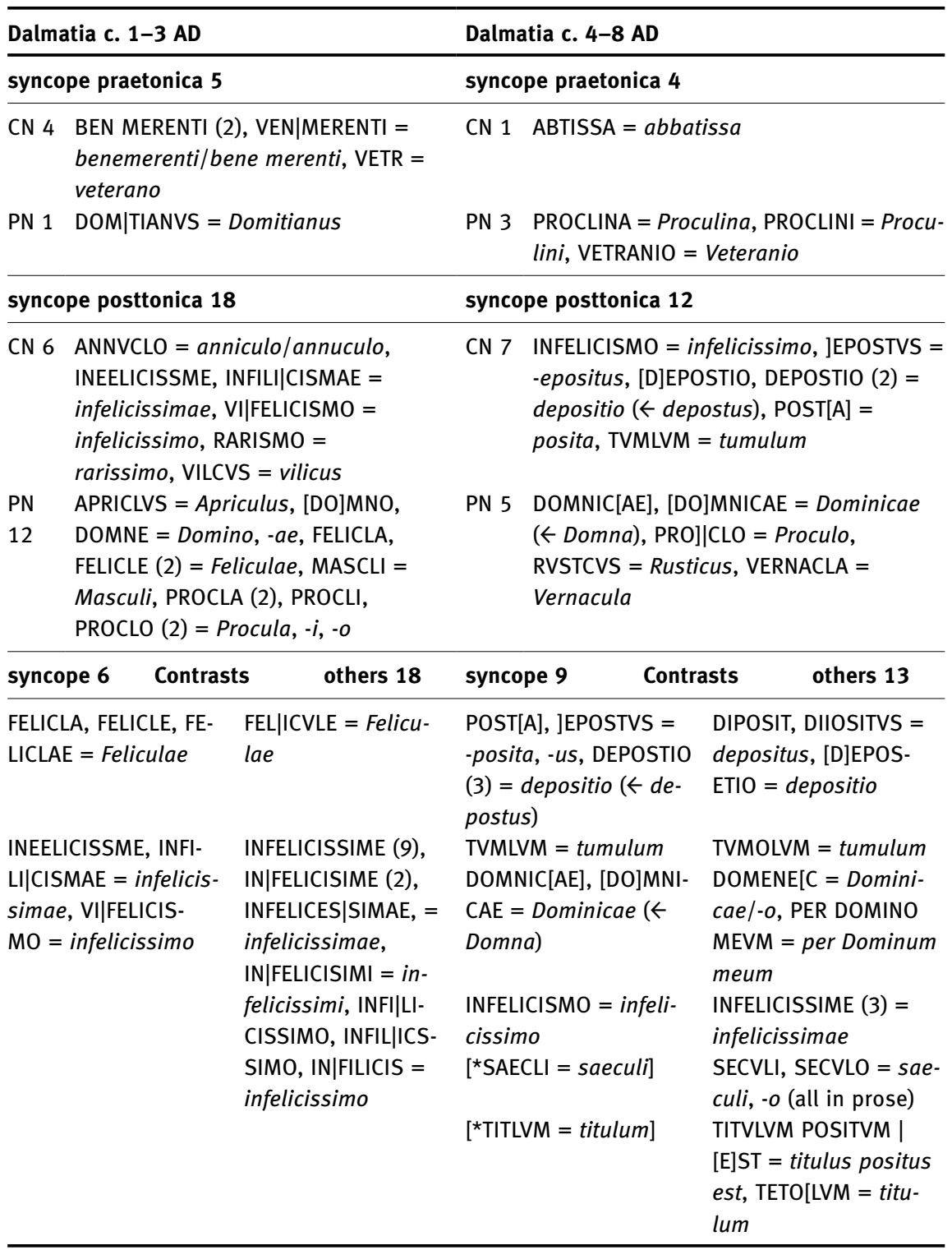


early $55 \%(55 \%+0 \%)$ up to later $89 \%(63 \%+26 \%)$, parallel to the decrease of syncopes. ${ }^{28}$

Despite this radical decrease of syncope we might nevertheless assert that syncope remained a quite vivid and relatively frequent phenomenon in later Dalmatia, as well. This general impression might be corroborated by the contrastive data displayed in Table 5 under the subheading Contrasts.

In both investigated time spans of Dalmatia we could match several syncopated and unsyncopated but otherwise misspelled counterparts of the proper noun Felicula and of the superlative infelicissimus: as for early Dalmatia on the side of FELICLE and INFILI|CISMAE (all 3 times in varying forms) stand FEL|ICVLE (once) and INFELICES|SIMAE (17 times in varying forms). As for later Dalmatia we were able to register even more nouns in their syncopated and unsyncopated but otherwise misspelled variants than in the early province: not only the syncopated INFELICISMO (for infelicissimo) has its unsyncopated but vulgar counterparts INFELICISSIME (3 times in varying forms for infelicissimae), but we could match two syncopated DOMNICAE (for Dominicae) to an unsyncopated but otherwise vulgar variant DOMENE[C (for Dominicae or Dominico), a syncopated TVMLVM to an unsyncopated but vulgar TVMOLVM, two syncopated POSTVS forms to two unsyncopated but vulgar DIPOSITVS and finally three DEPOSTIO, syncopated as for their root-word depostus, to one unsyncopated but otherwise vulgar [D]EPOSETIO. To some extent, however, this optimistic picture must be modulated by involving also the instances where only the unsyncopated but otherwise misspelled variants exist, as in the case of SECVLI and TETO[LVM] lacking their syncopated counterparts as ${ }^{\star}$ SAECLI and ${ }^{\star}$ TITLVM. In short, despite the relatively rich attestation of syncopated forms on the inscriptions of this province, the presence of this phenomenon in the Latin of later Dalmatia must not be overestimated and at the same time one should again take into consideration the massive decline of the frequency of syncope in view of the refined figures in the later province.

\section{Conclusions}

From this survey of the selected provinces we can draw the following, partly unprecedented conclusions.

28 As for the $e / i$ and $o / u$ mergers there have been recorded the following figures (Code-name: figure) from the early period: é > I : 1, í > E: 2, é: > I: 6, i > E: 7, e: > I: 9, e > I: 4 (= 29) and none for o/u!; from the later period: í $>$ E: 20, í: $>$ E: 1 , é $>$ I : 3, é: > I: 5, e: $>$ I: 7, e $>$ I: 14 , i: $>$ E: 3, i > E: $47(=100)$ and ú $>$ 0: 8, ó: > V: 6, ó > V: 3, u: > 0: 1, u > 0: 9, o: > V: 3, o > V: $11(=41)$ resp. 
Tab. 6

\begin{tabular}{l|lllllllllll}
\hline$\downarrow=$ decrease & \multicolumn{2}{l|}{ Aquitania } & \multicolumn{2}{l}{ Belgica } & \multicolumn{2}{l}{ Narbonensis } & \multicolumn{2}{l}{ Venetia-Histria } & \multicolumn{2}{l}{ Dalmatia } \\
\hline$\uparrow=$ increase & Diff. & Undiff. & Diff. & Undiff. & Diff. & Undiff. & Diff. & Undiff. & Diff. & Undiff. \\
\hline 1. Early & $\mathbf{4 5} \%$ & $4 \%$ & $\mathbf{5 0} \%$ & $5 \%$ & $\mathbf{2 9} \%$ & $\mathbf{2} \%$ & $\mathbf{3 6} \%$ & $3 \%$ & $\mathbf{4 5} \%$ & $5 \%$ \\
$\|=$ constant & $\downarrow$ & $\|$ & $\downarrow$ & $\downarrow$ & $\downarrow$ & $\downarrow$ & $\downarrow$ & $\downarrow$ & $\downarrow$ & $\downarrow$ \\
2. Later & $\mathbf{7} \%$ & $4 \%$ & $\mathbf{0} \%$ & $0 \%$ & $\mathbf{3} \%$ & $1 \%$ & $\mathbf{9} \%$ & $2 \%$ & $\mathbf{1 1} \%$ & $2 \%$ \\
\hline
\end{tabular}

1. Syncope was a quite frequent phenomenon in the Latin of all the selected areas in the early times of the Empire, i.e. in the first three centuries AD. ${ }^{29}$ In the early times of the Empire the frequency of syncope varies from region to region and according the data displayed in Table 6 we can rank the selected provinces as follows: in the early times syncope was most frequent in Belgica (50\%), then equally in Dalmatia (45\%) and Aquitania (45\%), then decreasingly frequent in Venetia-Histria (36\%) and the less frequent but still significant in Narbonensis (29\%).

2. Contrary to the early times syncope has become radically less frequent in the Latin of all the selected areas in the later times of the Empire, i.e. between the $4^{\text {th }}$ and $7^{\text {th }}$ or $8^{\text {th }}$ century $\mathrm{AD}$, and in one case, i.e. in Belgica syncope completely disappeared from the Latin of the area. Also in later times the frequency of syncope varies from region to region but with smaller amplitude, according to the smaller frequency figures recorded for each province. The ranking of the selected provinces has considerably changed: according the data displayed in Table 6, in the later period syncope was most frequent in Dalmatia (11\%), then decreasingly frequent in VenetiaHistria (9\%) and Aquitania (7\%), even less frequent in Narbonensis (3\%) and it completely disappeared from Belgica (0\%). The most radical change we could notice turning from early to later times was the radical evanescence of syncope in Belgica ( $50 \%>0 \%$ ), already observed by Herman. In addition the results displayed in table 6 completely refute the current assumption that envisages a gradual and accelerating spread of syncope in the Latin of the Empire in the course of time..$^{30}$

29 This picture sketched here corresponds well with the rich findings of syncope recorded by Väänänen (31966: 43-45) from the graffiti and inscriptions of Pompeii that are dated mostly for the time span of 62-79 AD cf. Väänänen ( $\left.{ }^{3} 1966: 14\right)$.

30 E.g. Lloyd (1987: 199f.) "Syncope can ... be conceived of as a variable rule of Latin which gradually expanded to more and more words and to more and more phonological conditions until finally it became a categorical rule of the language ...” (cited by Adams 2013: 100). 
3. If we compare the Latin and the Romance findings of syncope, we cannot observe any correlation or connection between the geographical distribution and frequency of syncope in Latin and in Romance: neither the pervasive syncope in Old French and Old Occitan, nor the radical syncope in Dalmatian ${ }^{31}$ have their forerunners or antecedents in the Latin inscriptional material of later Roman Gaul or Dalmatia. Of course this observation is not a very new one in the literature, but as for the Latin material this was proved with the help of statistical methods perhaps for the first time. What is more, we were able to detect such a sharp contrast between the more and more intensifying and increasing $o / u$ and $e / i$ mergers and the more and more decreasing and evanescent syncope phenomena that not only the alleged massive attestation of syncope in late Latin but even the existence of a widely assumed "common (pan-Romance) core" of Romance syncope has become highly questionable.

\section{Bibliography}

Adamik, B. 2009. In memoriam József Herman: von der Late Latin Data Base bis zur Computerized Historical Linguistic Data Base of Latin Inscriptions of the Imperial Age, "AAntHung" 49. 11-22.

Adamik, B. 2012. In Search of the Regional Diversification of Latin: Some Methodological Considerations in Employing the Inscriptional Evidence, in Latin vulgaire - latin tardif IX. Actes du IXe colloque international sur le latin vulgaire et tardif, Lyon, 6-9 septembre 2009, eds. Fr. Biville/M.-K. Lhommé/D. Vallat, Lyon. 123-139.

Adams, J. N. 2013. Social variation and the Latin language, Cambridge.

Cross, E. 1930. Syncope and Kindred Phenomena in Latin Inscriptions: from the Parts of the Roman World where Romance Speech Developed, New York.

Gaeng, P. A. 1968. An Inquiry into Local Variations in Vulgar Latin as Reflected in the Vocalism of Christian Inscriptions, Chapel Hill.

Herman, J. $1984=1990$. L'evolution du latin dans les provinces de l'Empire. Problèmes et perspectives, in id. Du latin aux langues romanes. Études de linguistique historique, ed. S. Kiss, Tübingen 1990. 55-61 (= Proceedings of the VII ${ }^{\text {th }}$ Congress of the International Federation of the Societies of Classical Studies 2, ed. J. Harmatta, Budapest, 1984, 305-310).

Leumann, M. 1977. Lateinische Laut- und Formenlehre, München.

Lloyd, P. M. 1987. From Latin to Spanishl: Historical Phonology and Morphology of the Spanish Language, Philadelphia.

Loporcaro, M. 2011. Syllable, Segment and Prosody, in The Cambridge History of the Romance Languages: Volume 1, Structures, eds. M. Maidenm, J. C. Smith and A. Ledgeway, Cambridge. 50-108, 684-689.

31 Cf. Mihăescu (1993: 98). 
Mihăescu H. 1993. La langue dalmate, in id. La romanité dans le sud-est de l'Europe, Bucureşti. 91-130.

Omeltchenko, S. W. 1977. A Quantitativ and Comparative Study of the Vocalism of the Latin Inscriptions of North-Africa, Britain, Dalmatia and the Balkans, Chapel Hill.

Väänänen, V. ${ }^{3} 1981$. Introduction au latin vulgaire, Paris.

Väänänen, V. ${ }^{3} 1966$. Le latin vulgaire des inscriptions pompéiennes, Berlin.

Zamboni, A. 1965-66. Contributo allo studio del latino epigrafico della X Regio Augustea (Venetia et Histria). Introduzione. Fonetica (Vocalismo), "AAPat” 80. 463-517. 